\title{
Solidaridad con los pobres
}

\author{
José María Tojeira, S.J.
}

\begin{abstract}
Resumen
En este artículo el autor expone la situación de pobreza que prevalece en el mundo, especialmente en los países del tercer mundo. Señala los múltiples factores que la originan y perpetúan, y que con toda su complejidad es, al final, producto de estructuraciones sociales humanas, de intereses humanos. Que los recursos para contrarrestarla existen, pero no la voluntad ni una política para combatirla. De allí que el espíritu de solidaridad con los pobres tiene diversas posibilidades de expresión, siendo una de ellas, en principio, la convicción de que el ser humano es igual en dignidad.
\end{abstract}

\section{Introducción}

Hablar sobre el tema de la solidaridad con los empobrecidos del Tercer Mundo supone el inicio de una peregrinación, de un largo camino por la realidad de seres humanos, idénticos en dignidad a nosotros, que sufren injusticias procedentes, en su mayor parte, del modo de organizar el mundo desde los intereses de los poderosos. Un caminar en el que a cada paso se va descubriendo lo entretejida que está nuestra existencia con el dolor de tanta gente. $Y$ un abrir los ojos a la sinuosa y maligna interrelación de temas como injusticia, pobreza, violación a los derechos básicos de la persona, reducción e incluso aniquilación de la dignidad humana. Se trata, en definitiva, de un recorrido en busca de la experiencia de humanidad. Esa experiencia que no estará nunca completa mientras un hermano o hermana mía esté sufriendo hambre, sea torturado, permanezca en la más absoluta marginación o sea asesinado cuando quiera desarrollar sus propios valores. Más que señalar una ruta concreta en un itinerario en el que la realidad de cada uno determina posibilidades, ritmos y compromisos concretos, quisiera partir de una descripción amplia de la situación de la pobreza en el mundo para después concentrarme en algunas posibilidades de solidaridad. Comienzo así con el dato más inmediato de la pobreza: la enorme dimensión de su tamaño.

1. Rector de la Universidad Centroamericana "José Simeón Cañas". 


\section{Pobreza: una cuestión de muchedumbre}

"Los pobres son muchos, por eso, es imposible olvidarlos". Con estas palabras introducía el poeta hondureño Roberto Sosa la colección de poemas con la que ganó en España el premio Adonai hace ya más de 25 años. Y esa afirmación sigue siendo hoy la realidad predominante en el mundo de los pobres: Son muchos, son demasiados, están y aparecen por todas partes, especialmente en los países del Tercer Mundo.

Hablar de 1300 millones de pobres nos puede parecer ya mucho, sobre todo si tenemos en cuenta que estamos hablando de pobreza extrema. Pero si comenzamos a hacer comparaciones entre niveles de vida y acceso a la riqueza, el mundo de la desigualdad agranda lo que podemos entender por pobreza. Y si a esto sumamos la tendencia a la concentración de la extrema pobreza y la extrema riqueza en el 20 por ciento más pobre o más rico, respectivamente, de la humanidad, el escándalo ante la situación no tarda en llegar. En 1996, el Informe del Programa de las Naciones Unidas para el Desarrollo, PNUD, aseguraba que las 358 personas más ricas de la humanidad poseen juntas un capital equivalente al ingreso anual del 45 por ciento de la humanidad (más de 2000 millones de personas). Sólo dos años más tarde el mismo informe en su edición del 98 afirma que "estimaciones nuevas indican que los 225 habitantes más ricos del mundo tienen una riqueza combinada superior a un billón de dólares, igual al ingreso anual del 47 por ciento más pobre de la población mundial (2 500 millones de habitantes)".

Desglosando en ejemplos este tipo de afirmación, el informe citado continúa haciendo comparaciones. "Las quince personas más ricas tienen activos que superan el Producto Interno Bruto total del África subsahariana”. Las 84 personas más ricas superan, con sus activos, el producto interno bruto de la China, con sus 1200 millones de habitantes. Continuando con los contrastes, el 4 por ciento de la riqueza de estos 225 millonarios (44 000 millones de dólares) sería suficiente para cubrir las necesidades de enseñanza básica, salud básica, salud reproductiva, alimentación suficiente y agua potable, para toda la población mundial que hoy carece de estos bienes.

Muy probablemente podremos vivir toda nuestra vida sin conocer a ninguno de estos 225 millo- narios. Pero lo que no podremos es no cruzarnos en la calle, casi a diario, incluso en el primer mundo, con alguna persona víctima de la pobreza. Si saltamos al tercer mundo la visión de la pobreza es tan permanente como el verde en los trópicos húmedos. En Brasil, uno de los países del tercer mundo con mayor potencia económica, el 50 por ciento de la población más pobre recibía, en 1995, el 11.6 por ciento del ingreso nacional; mientras que el 10 por ciento más rico recibía el 63 por ciento del mismo ingreso. $\mathrm{Y}$ aunque este 10 por ciento pueda establecer colonias residenciales en las que los pobres no puedan entrar, basta salirse mínimamente de los muros para encontrarse con los efectos, de todo tipo, de una sociedad profundamente desigual. Incluso en los países desarrollados, la negación de la igualdad de oportunidades en el campo de la salud y la educación convierte en verdaderos excluidos a muchos de sus ciudadanos.

En la medida, además, que abramos los ojos a este fenómeno omnipresente de la pobreza, veremos que impulsa profundas disparidades no solamente en el ámbito socioeconómico. Pobreza significa también debilidad, y por ello no debemos extrañarnos de que la pobreza se cebe especialmente en los más débiles. A la ya diferencia establecida entre pocos que tienen mucho y muchos que tienen cada vez menos, se suma la relativa situación de inferioridad de las zonas o personas desprotegidas a causa de la cultura, los intereses económicos o políticos, etc. En El Salvador, por ejemplo, la tasa urbana de analfabetismo es en la ciudad únicamente del 12 por ciento. Pero en el campo la misma asciende al 36 por ciento. Dando un salto hacia la pobreza más europea, podemos también contemplar que en Rumania mientras las viviendas urbanas tienen agua potable en un 88 por ciento de los casos, en las zonas rurales solo el 16 por ciento de las viviendas gozan de este beneficio.

Debemos hablar, además, de la feminización de la pobreza. En efecto, aunque en algunos aspectos, como en la alfabetización, las diferencias entre la mujer y el hombre han disminuido sistemáticamente en los últimos años, todavía se pueden encontrar profundas desigualdades en el ámbito de las oportunidades de participación en la vida económica y política. Situación ésta que empeora según se va descendiendo en la lista del subdesarrollo. Mientras en Europa la cifra de mujeres que mueren por cada cien mil niños nacidos vivos no 
suele pasar de la decena, en los países en vías de desarrollo llegan a cifras como las de 300 en El Salvador, 600 en Bolivia o 1000 en Haití.

La etnia y la raza han sido, así mismo, rasgos distintivos de la pobreza. Y lo siguen siendo tanto en nuestras sociedades ricas como las empobrecidas del tercer mundo. Según cifras de comienzos de los años noventa, en Alemania vivía en la pobreza el 11 por ciento de la población. Pero si sólo se toma en cuenta el número total de residentes extranjeros y se les aplican los mismos baremos que a la sociedad en general, resulta que el 24 por ciento de los mismos vive en pobreza. En Estados Unidos, mientras sólo el 6 por ciento de los blancos entre los 25 y 65 años no han completado el noveno grado, el número de hispanos en la misma situación asciende al $\mathbf{3 1}$ por ciento.

Las enfermedades y las guerras golpean también con mayor severidad a los más pobres. El sida, que comienza a tener un crecimiento regresivo en Europa, continúa haciendo estragos en el tercer mundo. De las 16000 personas que se contagian diariamente con esta enfermedad, el 90 por ciento vive en los países subdesarrollados. En Zimbawe la esperanza de vida se ha reducido ya en 16 años debido al sida, y en algunos países africanos se habla de un contagio que, según cálculos conservadores, alcanza al 25 por ciento de la población entre los 15 y 50 años. En Honduras la esperanza de vida al nacer ya ha sido reducida por la extensión del sida, y si la situación no mejora rápidamente habrá descendido, desde la actualidad hasta el año 2010, cinco años más. El Salvador, con los datos incipientes que tenemos, corre el peligro de seguir el mismo camino.

Las guerras y el armamentismo, además de desviar enormes recursos que podrían contribuir eficazmente al desarrollo de los pueblos, afectan de nuevo a los más pobres. A mediados de los noventa se hablaba de una población de refugiados de 19 millones de personas. Por supuesto provenientes de los sectores más empobrecidos de su propios países. Las bajas civiles en las guerras, que a principios de siglo se contabilizaban en un 5 por ciento del total de las muertes, han pasado en los noventa a constituir el 90 por ciento de las víctimas. Según, de nuevo, el informe de las $\mathrm{Na}$ ciones Unidas, son los más débiles los que pagan con mayor sufrimiento el tributo que la barbarie de la guerra impone: "En el último decenio han muerto en conflictos armados 2 millones de niños,

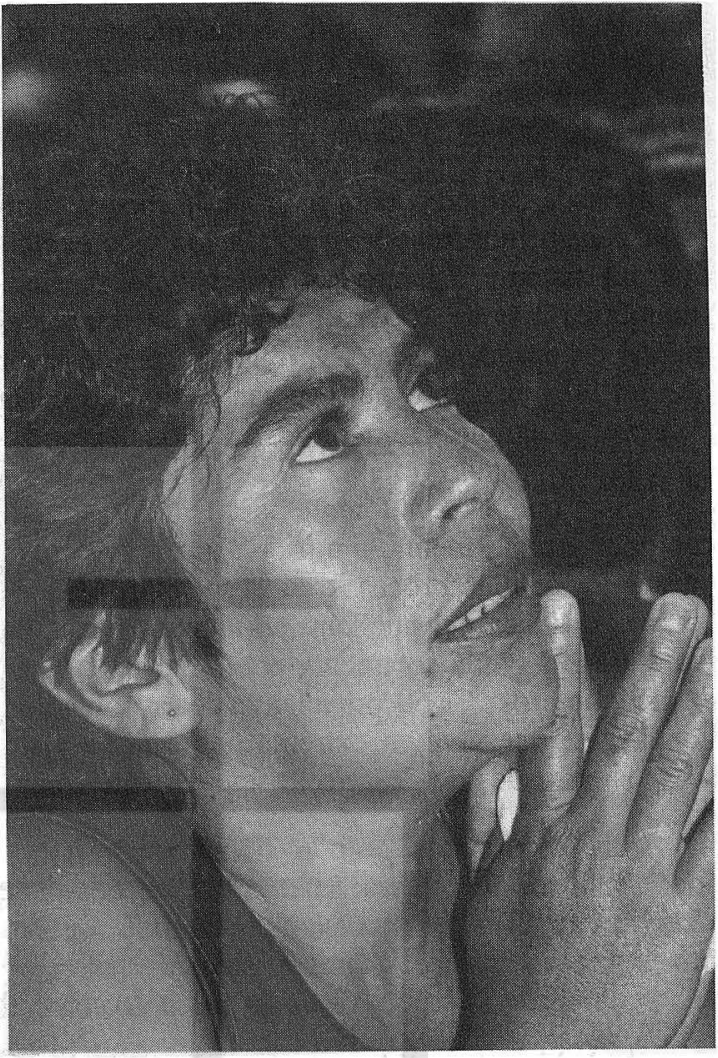

han quedado discapacitados de 4 a 5 millones, y 12 millones más han quedado sin hogar". En Chechenia, durante la guerra que sus habitantes mantuvieron con Rusia, el 40 por ciento de las bajas civiles fueron niños. Los 131 niños - con un promedio de edad de seis años- asesinados en 1981 en el caserío de El Mozote, El Salvador, cuyos esqueletos fueron desenterrados 12 años más tarde, eran campesinos. Una masacre de esas proporciones hubiera sido impensable en la ciudad, incluso en los momentos más duros de la guerra civil.

Las políticas económicas, especialmente en estos tiempos neoliberales, pueden también revertir los procesos de desarrollo, o al menos hacerlos menos equitativos. En países desarrollados como Estados Unidos, Nueva Zelandia o Inglaterra, que tuvieron un aceptable crecimiento medio entre 1975 y 1995, la proporción de la población que vive en la pobreza aumentó. En nuestros países en vías de desarrollo el efecto fue mucho más feroz, duplicando en ocasiones la reducción del ingreso en el sesenta por ciento de la población, incluso en 
momentos en que los indicadores macroeconómicos reflejaban crecimiento en el país.

Los desastres, finalmente, complican el panorama de la pobreza y al mismo tiempo que revierten años de esfuerzo para salir de la misma, golpean con infinita mayor dureza a los más excluidos del sistema. El huracán Mitch dejó en Centroamérica más de 10000 muertos y otro tanto al menos de desaparecidos. De ellos se puede decir que un 90 por ciento pertenecían al ámbito de la pobreza. Y aunque la solidaridad de los países desarrollados ha sido notable en su generosidad, no cabe duda que, especialmente para Honduras y Nicaragua, esta tormenta significará un grave freno en sus ya débiles procesos de desarrollo. Más de 15 días después del huracán, en algunas zonas de Honduras la ayuda solamente podía llegar a través de helicópteros. El 60 por ciento de la población hondureña, que vive en extrema pobreza, ha visto sus posibilidades de desarrollo severamente frenadas.

Aunque la narración de este mundo amplio y abundante de la pobreza puede resultar deprimente, no hay duda que a la hora de hablar de solidaridad se impone un recorrido, aunque sea parcial, por el mismo. Sobre todo cuando todo el sistema de funcionamiento de comunicación masiva contribuye, tanto en el primer como en el tercer mundo, al ocultamiento de la realidad. Especialmente de la realidad estructural oprimente. El dolor de las catástrofes inocultables se abre paso con relativa facilidad. La brutalidad de las masacres escandalosas está con frecuencia sometida a condicionamientos políticos y de otro tipo. Pero las relaciones de dependencia de los países pobres, las injusticias que el norte puede cometer con el sur, la barbarie o los abusos de los aliados en el campo de los derechos humanos, se someten, en el terreno informativo, con demasiada frecuencia, a las conveniencias oficiales o semioficiales.

\section{La pobreza, realidad violenta}

Estamos acostumbrados a considerar la pobreza como fuente de violencia. En efecto, hasta parece lógico que aquel que es muy pobre, por desesperación, hambre, envidia, falta de forma- ción, etc., pueda cometer delitos, especialmente contra la propiedad de otros. Pero estamos poco acostumbrados a ver cierto tipo de riqueza como un acto de violencia. Podemos entender que la ostentación y el derroche del banquete en medio de una sociedad hambrienta pueda resultar violento. Pero nos cuesta más trabajo el percibir que las desigualdades mundiales, queridas y planificadas en su conjunto por quienes llevan el pulso y el control de las economías, puedan ser actos de violencia. Sin embargo, en un mundo de hermanos, el hecho de que a lo largo de los últimos 40 años hayan aumentado las diferencias, ya de por sí abismales, entre el sector más rico de la humanidad y el sector más pobre, constituye una clara negación de la igual dignidad de los hermanos. Y si esa diferencia galopante se debe en buena parte a estructuras de relación comercial, política, económica, etc., podemos entonces comenzar a hablar de violencia estructural.

Algunos ejemplos, tomados nuevamente del informe del PNUD de 1998, pueden darnos simbólicamente una idea. $\mathrm{Si}$ yo, bien nutrido, pasara sistemáticamente comiendo helados al lado de una persona desnutrida y hambrienta, más de alguno pensaría que la estoy provocando. ¿Por qué, entonces, no pensar de la misma manera ante situaciones estructurales? Porque resulta que en Europa el consumo de helados significa un gasto de 11000 millones de dólares al año. Y que con 13000 millones de dólares se podrían cubrir las necesidades anuales de salud y nutrición básicas de la población mundial que carece de las mismas. Pero, todavía más grave, estos mismos contrastes se repiten dentro del mundo de la pobreza: con el 12 por ciento del gasto militar anual de los países en vías de desarrollo se podría dar atención primaria de salud a los 1000 millones de personas que en dichas regiones nunca van al médico. Vacunar, además, a los dos millones de niños que mueren anualmente en los mismos países a causa de enfermedades eliminables con vacunas. Y dar también agua potable a los 1300 millones de seres humanos que carecen de la misma y que tienen como una de las principales causas de morbilidad y mortalidad las infecciones gastrointestinales. 
Muchas de las guerras internas del tercer mundo, llámense civiles, sucias, etc., han tenido, como una de sus causas, las terribles e injustas diferencias sociales. El mundo de la pobreza extrema impone más pobreza en los rubros de educación, salud, vivienda, etc. Y simultáneamente implica una marginación que excluye al empobrecido incluso del Estado de Derecho. La desigualdad ante la ley, en sociedades donde el dinero se convierte de hecho en el valor prioritario, es una de las invitaciones más duras a la violencia y a la imposición de una especie de ley de la selva.

No es extraño que frente a esta violencia institucional se levante la violencia delictiva. El bandolerismo social de siglos pasados, presente tanto en el primer mundo como en el tercero, se convierte ahora en la violencia desenfrenada del que a toda costa quiere salir rápida y eficazmente de la pobreza. Aunque la mayoría de los pobres de nuestro mundo aguantan su pobreza con una paciencia y esperanza desproporcionada a su situación, no puede resultamos extraño que algunos se rebelen con una fuerza y un furor tan primitivo como anacrónica es la situación en la que están sumidos. En un mundo que tiene capacidad para vencer la pobreza, ésta se convierte, en la medida en que se prolonga indefinidamente, en una realidad violenta y generadora de más violencia. "Comer primero, luego la moral" era el coro que repetían las prostitutas en una obra de teatro de Bertold Brecht. Y aunque en Europa el problema del hambre se ha superado, queda todavía un tercio de la humanidad sin seguridad alimentaria. Colectivo de personas que seguirá pasando hambre, o incluso podrá aumentar, si desde la fecha actual al 2025 no se duplica y distribuye mejor la producción mundial de alimentos.

En esta situación, la violencia subversiva, aunque nace en ocasiones con un matiz claro de autodefensa, no deja por ello de añadir mayor dolor y desesperación a nuestras sociedades. Más allá de las condenas de este tipo de violencia, la pregunta que permanece en pie es si se puede exigir a los pobres que no se rebelen, que respeten la legalidad establecida, etc., sin hacer cambios realmente estructurales que hagan avanzar a nuestras sociedades hacia una cada vez mayor real igualdad de opor- tunidades. Aunque el combate violento de la violencia estructural suele llevar generalmente a mayores males, no puede desestimarse la desesperación en la que sume la pobreza. El que desde una situación de comodidad censure la violencia reactiva de los pobres frente a la opresión en la que están, puede caer con suma facilidad en el fariseísmo. Beneficiado en el reparto mundial de la riqueza, aumenta la violencia estructural con su incapacidad de acercarse a la problemática de los pobres y luchar pacíficamente a su lado por la superación de su situación. Samuel Huntington, en su libro $E l$ choque de civilizaciones, hace un estudio sobre la violencia étnica y llega a la conclusión de que las guerras interétnicas se dan casi siempre cuando aumenta notablemente el crecimiento demográfico y cuando simultáneamente el número de jóvenes desocupados se multiplica. Aun en las interpretaciones culturalistas de las últimas guerras que han asolado a la humanidad, el factor pobreza aparece irremediablemente en los análisis.

La no-violencia activa, como respuesta a la violencia estructural, es vista con frecuencia por quienes defienden el sistema injusto como una especie de violencia. Aunque ello sea falso muestra, sin embargo, el esfuerzo de encubrimiento de la realidad que hacen determinadas instituciones cuando a alguien que habla proféticamente frente a la pobreza o la creciente desigualdad se le acusa de violento. En América Latina, la mayor parte de los mártires contemporáneos han sido víctimas de esta apreciación y han sido asesinados por una palabra que, si bien puede haber sido agria, era inequívocamente solidaria con los más pobres de sus países, no violenta, e infinitamente menos dura

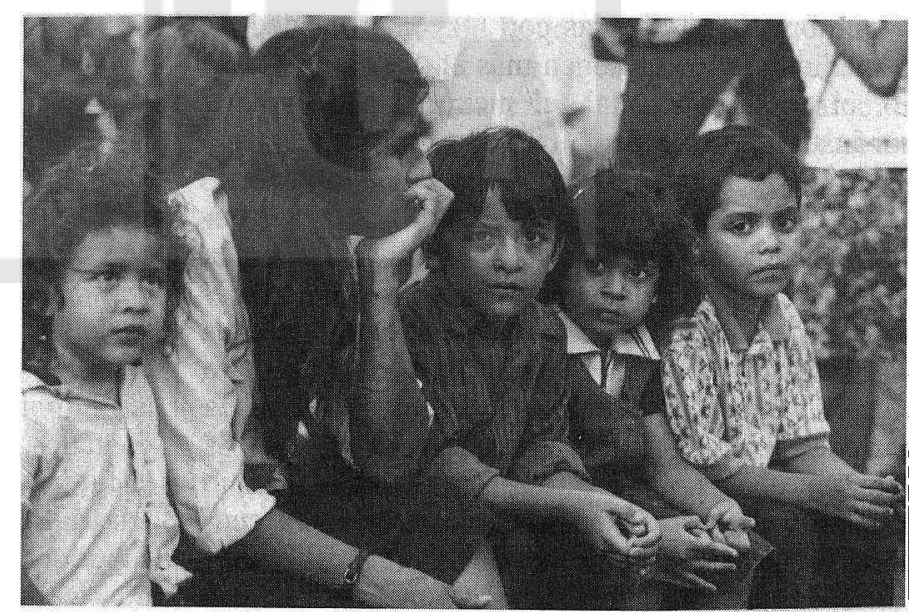


para los poderosos que la situación en la que estaban sumidos los pobres. En general, estos mártires de la no violencia se han ido convirtiendo en auténticos testigos de la situación de violencia estructural de nuestros países y de las aspiraciones de cambio de los mismos. Figuras como la de Monseñor Romero en El Salvador, o como los mártires jesuitas, permanecen como estímulo de un cambio pacífico, fratemo y racional a pesar de todo lo que sus detractores hicieron por desprestigiarlos o en favor de que se perdiera su memoria. Y demuestran, con sus vidas y con lo que su propia muerte genera de compromiso en muchas personas, que la no violencia activa es el mejor camino, si no el único, para superar la violencia estructural. La figura de Gandhi, asegurando la victoria de su causa desde el momento en que fue injustamente detenido, nos recuerda también la eficacia de la no violencia activa en un proceso de independencia que de otra manera hubiera sido infinitamente más doloroso y cruel. El asumir pacíficamente la suerte de los pobres y de sus luchas es el mejor camino para impactar a la conciencia de cualquier persona de buena voluntad con el testimonio de fraternidad.

\section{La pobreza realidad injusta}

La violencia contra el débil es siempre injusta. De hecho nuestras sociedades civilizadas reciben el nombre de civilizadas con mayor propiedad en la medida en que protegen más al débil. El huérfano, el enfermo mental, el menor, son atendidos por instituciones especializadas y gozan de protección legal. El abuso, de cualquier tipo, contra menores $\mathrm{o}$ inocentes, nos indignan. $\mathrm{Y}$ esta indignación expresa lo mejor de nuestra civilización: la conciencia de la igual dignidad de los seres humanos. En ese contexto, la existencia de grandes márgenes de pobreza y desigualdad en el mundo en que vivimos, muestra la incivilidad de nuestra sociedad a nivel global. Aunque es cierto que la solución de la pobreza no es tan automática como el extraer fondos de un rubro de prioridad secundaria y traspasarlos al mundo de los pobres, lo cierto es que los recursos para vencer los efectos más negativos de la pobreza existen, y que, al mismo tiempo, no hay voluntad ni personal ni política de administrar dichos recursos de tal manera que se den pasos eficaces hacia la eliminación de la pobreza, al menos en sus aspectos más denigrantes.

Y ahí está la raíz más profunda de la injusticia de la pobreza. Indudablemente ésta se debe a múltiples factores, históricos muchos de ellos. Pero eso no la convierte en una realidad natural. Con toda su complejidad, la pobreza es fruto, al final, de decisiones humanas, de estructuraciones sociales humanas, de intereses humanos. $Y$ toda construcción humana puede ser humanamente reverti$\mathrm{da}$, aunque esa tarea no tenga que ser necesariamente fácil. No es tan importante discutir si en el ayer se pudo hacer este esfuerzo por revertir el fenómeno de la pobreza, que excluye, margina $y$, en ocasiones, mata, a millones de seres humanos. Lo cierto es que hoy se puede, aunque el proceso deba ser lento y complejo. Y si ya en el ayer la pobreza, al menos en sus aspectos más deshumanizadores y/o dolorosos, se veía como una profunda injusticia, cuando al lado estaban los recursos que podían aminorarla, hoy no hay excusa. El mundo es cada vez más pequeño y la pobreza de unos contrasta violentamente con la riqueza de otros, negando la igualdad del género humano y pisoteando la dignidad de muchos. Y si además consideramos que al menos en parte la pobreza del tercer mundo está relacionada estructuralmente con la riqueza de los países ricos, la injusticia cobra tintes todavía más profundos.

Contra la conciencia de igualdad, y contra la decisión de dar pasos eficaces hacia ella, actúa permanentemente un hecho: nuestras estructuras sociales, costumbres, modos de actuar, tienden a construirse de un modo casi inconsciente en torno al binomio superior-inferior. Los relatos históricos contados por los vencedores en los que se ensalza la fuerza y dignidad de los mismos, el prestigio de los triunfadores, la propaganda que muestra como superior al que tiene mayor capacidad de consumo, la competitividad como norma en la escuela, 
en los negocios e incluso en la religión, nos van empujando a confundir el éxito con el valor de las personas. $Y$ nos van llevando insensiblemente a emitir juicios en los que el dinero, el color de la piel, la ciencia y los títulos adquiridos, la apariencia, la cultura estandarizada, se convierten en el criterio decisivo para catalogar como mejor o peor a quienes me rodean, como confiable o como sospechoso, como superior o inferior.

Dentro de esta tendencia, el binomio pobreza-riqueza ha sido frecuentemente un elemento más para clasificar

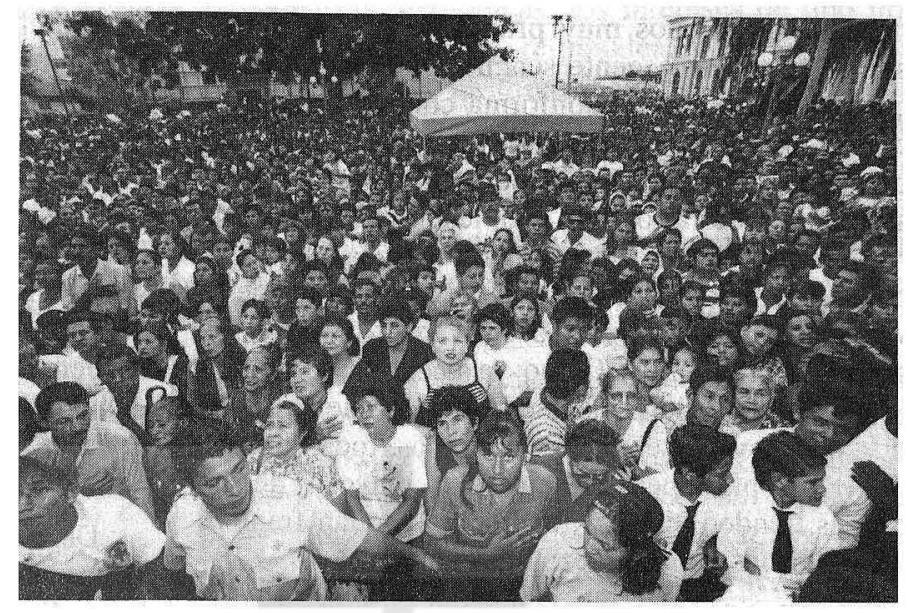
a la personas como buenas o malas. Incluso las religiones, y no faltan ejemplos en nuestra tradición cristiana, han presentado en ocasiones la riqueza como una beñdición de Dios, que de alguna manera da una mayor dignidad a quien la posee, especialmente si la administra correctamente, $o$ al menos favorece con ella a las mismas religiones.

Sin embargo, este modo de pensar daña severamente lo más profundo de cualquier concepción humanista, que parta de la radical igualdad en dignidad del ser humano, incluida nuestra propia fe cristiana. Diversidad, incluso en la tenencia de riquezas, siempre existirá. Entre otras razones porque incluso en un mundo donde la abundancia fuera la norma, siempre habría personas que optarían voluntariamente por cierto tipo de austeridad. Pero ello no excluye del compromiso con la dignidad del ser humano. En ese sentido, sin una auténtica conversión al mundo y realidad de los pobres, difícilmente podremos tomar las decisiones que se necesitan para superar la realidad injusta en la que vivimos.

\section{Lo que los pobres nos pueden enseñar}

Hablar sobre la realidad violenta e injusta de la pobreza no dejaría completa la reflexión. Aunque la pobreza, en el grado en el que produce marginación, indignidad o muerte, sea completamente condenable y sólo catalogable como mala, la realidad humana de los pobres muestra sorprendentemente una serie de valores del espíritu que se dan preferentemente en la dificultad. Igual que la guerra produce héroes, además de muertos, dolor y desborde de las más bajas pasiones humanas, también la pobreza hace que broten dimensiones pro-

fundamente enriquecedoras del espíritu humano, aun en medio de la injusticia y las perversiones.

El espíritu de solidaridad con los pobres nace inicialmente de la convicción de que el ser humano es, en cualquier lugar en el que esté, igual en dignidad. Cuando esa dignidad se niega a través de una pobreza estructural y real que es al mismo tiempo injusta y violenta para quienes la sufren, la persona que tiene experiencia de humanidad tiende siempre a la solidaridad. No se puede ser bueno en "el buen sentido de la palabra bueno", como diría Machado, sin ser profundamente humano. Y lo humano habla siempre de una real fraternidad e igualdad entre todos los que gozan del mismo calificativo.

Pero además de la experiencia de igualdad en dignidad, hay otros elementos que alimentan la solidaridad con los pobres, especialmente cuando se tiene una relación de largo plazo con ellos; y éstos son los valores que con frecuencia se generan en el mundo de la escasez. El más impresionante, a mi juicio, es la capacidad de los pobres de resistir en el bien. Aunque evidentemente muchos pobres sucumben a la desesperación que la misma pobreza lleva consigo en medio de un mundo que anuncia sistemáticamente promesas inalcanzables para ellos, la mayoría de los empobrecidos de la tierra resisten haciendo el bien. Resisten arando la tierra, realizando oficios marginales, esperando y luchando para que sus hijos no sufran las mismas penurias que ellos, transmitiendo un mensaje de bondad, honradez y trabajo a quienes vienen detrás de ellos. Si tuviéramos que preguntarnos quién mantiene el mundo en su sensatez y funcionamiento 
normal, tendríamos muy probablemente que pensar, al final, en la gente sencilla que simplemente quiere vivir y que se conforma con su sencillez y con su esperanza de ir poco a poco resolviendo sus problemas. No son las más de las veces los poderosos de esta tierra los que mantienen el futuro de la humanidad, sino la gente buena y trabajadora que lucha con sudor y dificultades, desde condiciones a veces infrahumanas, por hacer avanzar un poco sus sueños y esperanzas. Como ya decía en su tiempo Francisco de Vitoria hablando de las guerras, "las más de las veces entre los cristianos, toda la culpa es de los príncipes". Mientras la mayoría de los pobres tienden al bien, los líderes vacilan frente a las idolatrías de la riqueza o el poder.

En El Salvador, en medio de la guerra civil de 12 años que asoló el país, los pobres, que tenían motivos para odiar, pues fueron los que más sufrieron, se distinguieron también en su capacidad de riesgo a la hora de hacer el bien. Cuando cientos de campesinos que no querían dejar sus tierras se desplazaban sin hogar por zonas de guerra, encontraron casi siempre a otros campesinos que les daban eventualmente comida y posada, aun sabiendo que a los ojos del ejército eso era delito. Incontables fueron la personas en el mundo de los pobres que arriesgaron su seguridad personal por servir a las víctimas de la guerra.

Es cierto que en la pobreza injusta, que margina y humilla, se dan también terribles deformaciones de humanidad. Desde la promiscuidad y el abuso infantil hasta la falta de fidelidad a valores básicos en medio de la desesperación por salir adelante, la pobreza genera todo un mundo de injusticias en las que el mismo pobre roba, engaña, oprime o mata al pobre. Pero también sigue siendo cierto que en medio de la doble realidad de injusticia, la que oprime desde fuera y la que destruye desde dentro, los pobres siguen siendo en nuestros pueblos la fuente de esperanza, solidaridad y ejemplo más notable y constructiva. $\mathrm{E}$ incluso nos indican con una gran sencillez, los elementos culturales que deben ser parte de una nueva humanidad.

En efecto, los pobres saben vivir en austeridad, y sin un componente de este valor en nuestras culturas difícilmente podremos ser solidarios. Un mundo que privilegie el derroche seguirá siendo un mundo que cree pobreza, porque un mundo tan densamente poblado como el nuestro tiene cada vez menos margen para el derroche y el despilfarro. Los pobres saben compartir desde su pobreza, porque el propio dolor de sus carencias les ayuda a comprender el sufrimiento de quienes carecen de lo mismo que ellos o tienen todavía menos. Y los pobres saben también festejar la esperanza, la hermandad que los mantiene vivos y los pequeños destellos de bonanza que de vez en cuando se presentan en sus vidas. Sin austeridad, solidaridad y sentido festivo de la vida, difícilmente podremos construir un mundo diferente del actual, marcado en demasía por el individualismo insolidario, las grandes diferencias injustas y la indiferencia ante el dolor de quien sufre privaciones en sus necesidades básicas y en su dignidad.

Desde el punto de vista cristiano, en América Latina solemos decir que los pobres nos evangelizan. Fue ésta la experiencia de Monseñor Romero en El Salvador y la de muchos sacerdotes, religiosas y voluntarios que acompañaron a los pobres en sus sufrimientos. Aun en medio de la deshumanización que crea la pobreza injusta, el espíritu humano reproduce, aun con clima adverso, los mejores ejemplos de solidaridad y austeridad: dos valores sin los cuales no podremos construir un mundo con mayor justicia y con un creciente respeto y reconocimiento de la igual dignidad de los seres humanos. En este contexto es muy frecuente escuchar a las personas que han estado cerca de los excluidos de esta tierra en su peregrinación dolorosa hacia una mayor justicia y dignidad, diciendo que ha sido más lo que han recibido de los pobres que lo que ellos les han dado. $Y$ eso aunque hayan dejado atrás comodidades, hogar y reconocimiento profesional, por acompañar a quienes en muchos círculos y ambientes son tenidos por nada. Las palabras de Pablo a los Corintios, en el marco de los sufrimientos de la primera predicación del cristianismo, se convierten para muchos en un reflejo real de su experiencia vivida al lado de los pobres de este mundo, tanto desde la fe religiosa como desde una fe puramente humanista: "Atribulados en todo más no aplastados; desconcertados pero no desesperados; perseguidos pero no abandonados; derribados pero no aniquilados".

\section{La solidaridad, una deuda de la existencia}

Después de recorrer las terribles diferencias que separan al género humano, la interminable historia de dolor que generan y los valores que desde su pobreza nos siguen ofreciendo nuestros hermanos marginados, no se puede dudar de que estamos en deuda con quienes mantienen su espe- 
ranza en medio de la exclusión y el olvido. En este sentido es necesario que hagamos un recorrido por aquellos aspectos de la solidaridad que hoy son indispensables para que el concepto de humanidad pueda sobrevivir en medio de la negación sistemática de sus valores básicos, en masacres, hambre, marginación de género, sufrimiento y muerte sistemática de inocentes. La voz con la que se inicia la historia bíblica (el Paraíso era la prehistoria), "Caín, qué has hecho con tu hermano Abel", sigue hoy sonando en nuestros oídos al abrir los ojos a este mundo marcado por la multitud de los pobres y por sus múltiples sufrimientos. Contestar a esta pregunta significa el comienzo del recorrido de una larga serie de situaciones en las que debemos comprometernos.

(a) Las grandes catástrofes, naturales o históricas, constituyen una primera llamada a la solidaridad. Llamada de urgencia, a veces difuminada en las luchas de intereses, impactante siempre cuando se descubre. La reciente tragedia centroamericana ha sido un caso más de catástrofe natural, con terribles costos para países con una larga historia de dependencia, marginación y pobreza, que experimentan de pronto una marcha atrás que les hace retroceder $\mathbf{2 0}$ o más años. Y aunque la reacción ha sido generosa, tanto a nivel interno como externo, las heridas y las consecuencias perdurarán por años. El huracán Fifí, que asoló Honduras en 1974, fue recordado durante varios años, no sólo por la muerte y el dolor que dejó a su paso, sino por las graves pérdidas materiales y el costo de entre cinco y seis años para recuperarse de la devastación.

Aunque frente a las grandes tragedias naturales la solidaridad brota con rapidez, no está de más el recordar la frecuente insuficiencia de los esfuerzos solidarios. Las hambrunas en el África subsahariana han dejado siempre un rastro de dolor y muerte que la solidaridad no ha podido controlar eficazmente, aunque haya atemperado las dimensiones de la tragedia.

Frente a las catástrofes históricas, la reacción solidaria ha sido más compleja. Ante el genocidio en Ruanda, la reacción internacional fue solidaria aunque poco eficaz. En Bosnia, tras muchos esfuerzos y dilaciones, se llegó a ejercer una presión suficiente para frenar la situación e incluso enjuiciar a algunos de los ejecutores de masacres. Sin embargo, frente a algunos auténticos genocidios, como el acontecido en Camboya durante el régimen de Pol Pot, la difusión de la situación fue mínima.
Las alianzas ideológicas, los intereses de tipo imperialista, las luchas regionales, interferían para negar lo que era un drama real de reducción, con métodos criminales, de un tercio de la población camboyana. El relativo silencio ante la masacre de los judíos, gitanos, etc., durante la segunda guerra mundial, no se puede explicar simplemente diciendo que las denuncias no eran públicas para impedir una aceleración o ampliación de la masacre.

Aunque la solidaridad inmediata ante las catástrofes naturales suele ser más rápida que la que se produce ante la brutalidad histórica, hay también algunas lecciones que debemos tener en cuenta. En primer lugar, ante las catástrofes naturales o históricas queda todavía como asignatura pendiente el recordar que las reconstrucciones son siempre a largo plazo. Una destrucción como la del huracán Mitch, con saldos de 1200 millones de dólares en El Salvador, en tomo a tres mil en Honduras, más de 1500 en Nicaragua, y daños de menor cuantía en Guatemala, no se arregla en una semana. Honduras, con una deuda externa de 4000 millones de dólares, vio cómo las perspectivas de su deuda casi se duplicaban si quería reconstruir los destrozos ocasionados por el huracán. Con el agravante de saber que si no se iniciaba pronto un plan de reconstrucción, las seiscientas mil personas que quedaron sin trabajo en un país ya pobre y con una oferta de trabajo limitada, se convertirian en un foco de inquietud y desasosiego social de imprevisibles consecuencias. En este contexto, la condonación de la deuda externa no es sólo una cuestión de generosidad, sino un presupuesto indispensable para que este país, ya pobre, pueda ser viable en el futuro.

En segundo lugar, la reconstrucción a largo plazo debe tener en cuenta la prevención. En El Salvador, un alto porcentaje de las tierras inundadas lo fueron a causa de la apertura de las compuertas de una de las presas que regulan el cauce del río Lempa, el de mayor caudal del país. Los sistemas de prevención funcionaron lo suficientemente mal como para que los campesinos fueran advertidos de la apertura de compuertas sólo con 15 minutos de anticipación. A pesar de conocerse el anuncio de la llegada de fuertes lluvias a causa del huracán Mitch, las represas salvadoreñas no se vaciaron antes de la llegada de las lluvias. El temor a que los pronósticos metereológicos no fueran exactos, junto con el miedo a vaciar los pantanos en las inmediaciones de la época seca, propiciaron un agravamiento del desastre. 


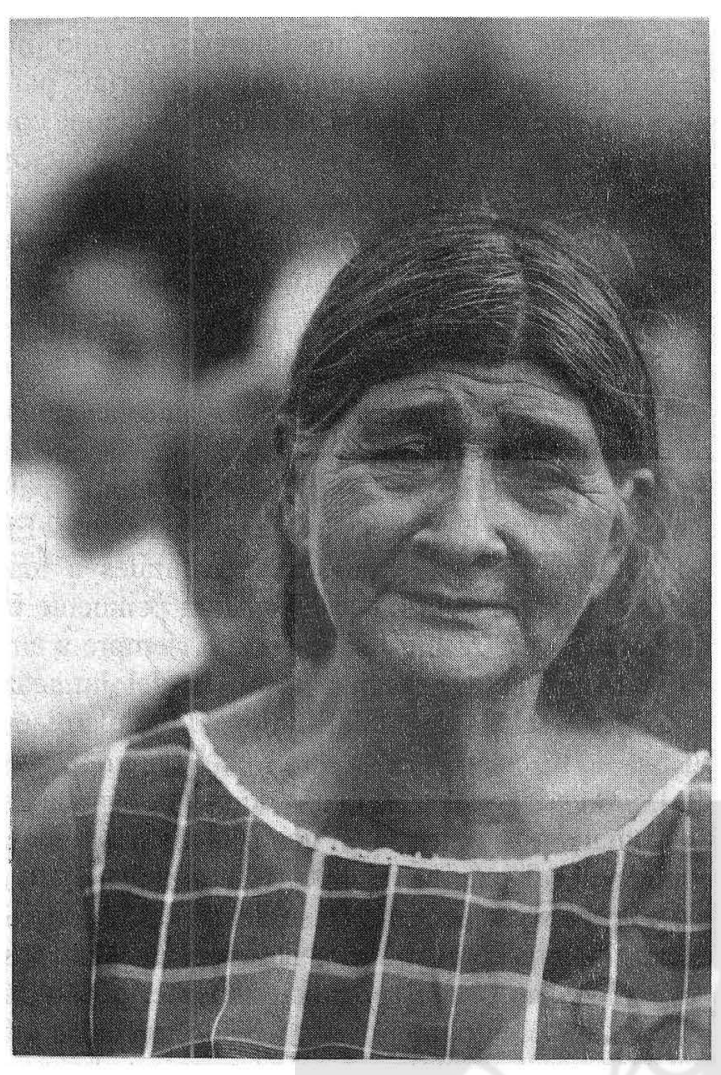

En otro orden de cosas, el terremoto de 1986 en San Salvador dejó mil muertos en la capital, 10000 heridos y doscientas mil personas sin hogar. Si hoy se repitiera un terremoto de la misma intensidad y duración no hay ninguna garantía de que el daño que sufra la población no vaya a ser mayor. La inversión en prevención del desastre, con mejoramiento de la normativa y supervisión de la construcción, con zonificación de áreas de peligrosidad, con investigaciones sobre ingeniería sísmica y organización de la población ante el desastre, ha sido muy diminuta. Y ello a pesar de que todos sabemos que reconstruir sin desarrollar la prevención del desastre es arriesgarse a retrocesos cíclicos que impidan a la larga un desarrollo real del país.

En el terreno de las catástrofes históricas, la prevención, en el sentido de impedir que se repita la brutalidad, tiene también sus propias leyes, muy pocas veces atendidas por la comunidad internacional. Para asegurar la paz a largo plazo de un país que ha sufrido las inclemencias de guerras civiles, con toda su secuela de muerte, desaparicio- nes, tortura y deshumanización, hay que realizar también acciones de largo plazo. Las tareas de educación en democracia, pluralismo, respeto a los derechos humanos y funcionamiento imparcial y eficaz de las instituciones que regulan la vida social y la interrelación de las personas, no pueden limitarse a un año ni a dos, sino que requieren de tiempos largos, con más conexión con el ritmo de las generaciones que con la unidades anuales. Frente al crimen de humanidad sólo un proceso de verdad, justicia, reparación de las víctimas y establecimiento de mecanismos legales de perdón, pueden permitir una eficaz reconciliación de las personas. Casos como el de la autorreceta de amnistías en muchos países latinoamericanos, o como el caso, hoy de actualidad, de la pretendida inmunidad de Pinochet en Chile, alargan los procesos de reconciliación y mantienen abiertas las heridas. Permitir que el verdugo prevalezca sobre la víctima es la mejor manera de posibilitar en el futuro la repetición del sufrimiento.

En ese sentido, la generosidad, siempre muy de agradecer, de nuestros pueblos ante las grandes desgracias naturales e históricas, debe complementarse con compromisos de largo plazo que impliquen reconstrucción y prevención. De lo contrario, las catástrofes se convertirán en el freno natural y periódico de muchos de nuestros pueblos del tercer mundo, manteniéndolos en la situación injusta que hemos descrito con anterioridad.

La problemática del intervencionismo, que suele surgir cuando se habla de una solidaridad necesariamente condicionada, realizada en el largo plazo y con los objetivos mencionados, suele ser hipócrita. Mientras los países desarrollados impulsan dinamismos, a veces de corte imperialista, en el mercado protegiendo sus ganancias y condicionando sus negocios, son al mismo tiempo demasiado tímidos para alentar la protección de los derechos humanos con ciertos condicionamientos.

(b) Al hablar de prevención estamos entrando en otro campo indispensable para la solidaridad. $Y$ se trata de la solidaridad en la eliminación de las causas que grosso modo generan dolor a la gran proporción de humanidad empobrecida o marginada y perseguida. El camino e instrumento de esta solidaridad, es la construcción y fortalecimiento de la sociedad civil. Y aunque esto parezca aparentemente obvio, en el campo de la solidaridad internacional no se tiene demasiado en cuenta. Con frecuencia las ayudas dependen más de los 
intereses políticos, económicos o militares que se tienen en determinados países, que de las necesidades objetivas de los mismos. Ello hace que al final los beneficiados de la ayuda internacional sean los gobiemos, o determinados partidos políticos en el poder, muchas veces empeñados en no cambiar las estructuras que mantienen en la pobreza a una buena parte de la población. Con todos los matices que se le pueden añadir al dato en bruto, el hecho de que los diez países con más pobres en el mundo (con más de la mitad de ellos dentro de sus fronteras) reciban solamente el 31.7 por ciento de la ayuda oficial de los países ricos, puede darnos una idea de la simpatías y antipatías políticas con las que se manejan algunos programas. El crecimiento de la sociedad civil y de sus instituciones es la garantía más clara de que el desarrollo se orientará hacia el beneficio de la población en vez de a las instituciones que las suplantan.

Y al hablar de estructuras, valga la aclaración, no estamos refiriéndonos a modos de producción en general, sino a cuestiones tan simples como, por ejemplo, la política fiscal. Países en los que hay un 40 por ciento o más de evasión fiscal en el impuesto sobre la renta, concentrado especialmente en los sectores altos, o donde el IVA se aplica de un modo no igualitario, dañando positivamente al productor agrícola, y que no están dispuestos a reformar un sistema que permite el mencionado tipo de abusos, difícilmente pueden mejorar la situación de los empobrecidos. Al contrario, lo previsible en estos casos es que la ayuda internacional se utilice en el reforzamiento del statu quo si se canaliza a través de los gobiernos. Sólo una sociedad civil desarrollada y fuerte puede cambiar los patrones de comportamiento de los gobiernos, demasiado acostumbrados al paternalismo, compadrazgo, corrupción y abuso de autoridad. Al aumentar la conciencia, la educación, la organización, la cultura democrática y ciudadana, la capacidad de gestión de los propios intereses, la sociedad civil se convierte en verdadera instancia de evaluación y transformación de los partidos, de los gobiemos e incluso del tipo de Estado en el que se quiere vivir.

Ayudar a la sociedad civil es contribuir no sólo al aumento de la producción, sino a que ese aumento de la producción redunde en un aumento de la capacidad de consumo de las mayorías. La ayuda internacional tiene esa doble virtualidad: puede contribuir a que la propia sociedad civil gestione sus necesidades en el campo de la educación, de la vivienda, de la salud, de la alimentación, o puede contribuir también, según sea su enfoque, a que se perpetúe la miseria de siempre. Apoyar los procesos que hacen que la gente - la gente normal con la que nos encontramos día tras día en el autobús, en el mercado y en la fábrica, la oficina o el campo- crezca en capacidad de conciencia y conocimiento de su dignidad y derechos, y se organice para defender y gestionar sus intereses ciudadanos, laborales, etc., es indispensable para garantizar un desarrollo justo. Programas de ayuda masiva sin tener en cuenta los esfuerzos y las perspectivas del hombre y la mujer de la calle (o de los caminos, que son tan abundantes o más que las calles en nuestros países), pueden servir, al contrario, para mantener situaciones de injusticia que nadie quiere.

(c) Y entramos así en un tercer aspecto de la solidaridad. Es evidente que hay que ser solidario ante el dolor inmediato del pobre. Pero simultáneamente debemos aprender que el camino de la solidaridad con el pobre no se vuelve eficaz si simultáneamente no nos solidarizamos con las causas de los pobres. Las formas de opresión en el tercer mundo, así como las luchas de los empobrecidos, son excesivamente variadas y no vamos a tratar de recorrerlas todas. Pero a la hora de solidarizarnos, debemos siempre preguntarnos hacia dónde van los programas o proyectos que queremos apoyar. Con frecuencia los empobrecidos de este mundo saben mejor lo que desean que cómo caminar hacia sus objetivos. Al contrario, lo que podríamos llamar "poderes terrenales", usando una antigua pero sugerente formulación, son maestros del cómo caminar en el día a día de la historia, aunque no sepan hacia dónde van. La conversión de un primer mundo rico y saciado, aunque no liberado de problemas, incluso socioeconómicos, así como la conversión de los sectores beneficiados que viven en la abundancia en los países del tercer mundo, pasa por la solidaridad con las causas de los pobres, por el compromiso con las mismas, y por el intento de ponerse al servicio de las concreciones históricas a la esperanza.

En este contexto queremos explicitar dos grandes causas históricas de los pobres. La primera es su propia liberación, sociocultural y económica. Las Democracias Cristianas de los años setenta gustaban de repetir como consigna la siguiente frase: "Sólo el pobre salva al pobre". Aunque, como a 
todo "slogan", a la frase se le pueda dar un claro componente demagógico, lo cierto es que los empobrecidos de nuestro mundo están encerrados en el círculo infernal de una conciencia de inferioridad, en muchos aspectos inducida o impuesta. El "tanto tienes, tanto vales" no es sólo una frase cínica que justifica modos de relación relativamente habituales. Es parte de un esquema en el que los términos superior-inferior relegan a una buena parte de la humanidad a la posición de desecho de la misma. Y es esa humanidad empobrecida, en tantos aspectos digna de admiración y de agradecimiento, la que tiene que salir de su situación rescatando su propia dignidad. A nosotros nos toca aprender, apoyar y ayudar sin paternalismos. Aclarando además que tan paternalista puede ser el querer imponer caminos concretos de desarrollo, como el disimular cualquier aberra-

ción que se dé en dichos procesos. El diálogo, la cercanía a las experiencias de los pobres, el análisis serio de los triunfos $y$ fracasos, deben ir marcando el ritmo de la solidaridad con esta lucha por la propia dignidad, que implica siempre la conquista de al menos un mínimo vital en el campo de las necesidades humanas que permita vivir decentemente.

La segunda causa, histórica y actual al mismo tiempo, son los derechos humanos. Después de largas décadas en las que la lucha fundamental en América Latina era defender los derechos básicos de la persona humana, como el derecho a la vida, a la integridad física, a la libertad y a residir en el propio país, nuestros pueblos se enfrentan ahora a un doble desafío diferente del que predominó hace todavía pocos años: la conquista de los derechos económicos y sociales y el lograr que las propias instituciones funcionen adecuadamente.

En nuestros países, lo que normalmente se conoce como el estado social es una realidad desconocida, salvo raras excepciones. Los derechos económicos y sociales están con frecuencia subordinados a la ley del más fuerte, lo que significa automáticamente su inexistencia. El Estado se preocupa más de los beneficios de quienes tienen influencia y poder y se convierte en un mecanismo de aceleración de la riqueza individual. Presidentes que llegaron medianamente ricos al poder, lo dejaron convertidos en miembros del discreto grupo de las cinco personas con mayor riqueza económica de su país. Hermanos de presidentes atesoraron fortunas millonarias fuera de sus propios países. Esposas, hijos, parientes, militares, etc., se sumaron al festival de la corrupción que acompanó a muchos de nuestros gobiemos. La llegada del pensamiento neoliberal, con su fe ciega en las virtudes del mercado, y con su seguridad de que la riqueza de los ricos produce un goteo de bienestar hacia abajo que acaba beneficiando a todos, terminó por remachar un estilo de Estado en el que brilla por su ausencia la compensación social a nuevas medidas de ajuste que vienen a agravar el problema de la pobreza (sin olvidar la aplicación de impuestos claramente regresivos).

Sin buscar modelos de estado burocráticos, autoritarios ni centralistas, los empobrecidos de nuestras tierras buscan hoy la construcción de un modelo de Estado en el que todas y cada una de las personas que viven en el país sean el principal foco de interés real. Donde la preocupación por las compensaciones sociales acompañe a las medidas de ajuste. Donde el impulso a la producción se dé en medio de la igualdad de oportunidades para los productores, donde el trabajo sea retribuido con un salario justo, donde el cuidado del medio ambiente sea considerado de beneficio nacional y la seguridad social sea una realidad universalizada.

En el campo de los derechos humanos fundamentales, la comunidad internacional ha adquirido una sensibilidad cada día mayor. El caso del general Pinochet, con todas las opiniones y discusiones originadas, es una muestra de ello. Sin embargo, la comunidad intemacional debía una vez más evitar la hipocresía. Está bien que se juzgue en el primer mundo a los asesinos y violadores sistemáticos de los derechos humanos, cuando en el tercero somos impotentes para hacerlo. Pero sin olvidar que precisamente a esta gente se la mantuvo muchas veces en el poder desde el primer mundo, se 
le vendió armamento y se le rindió honores. De nuevo la prevención se toma un elemento clave en la solidaridad. Que en este tema consistiría en sanciones eficaces contra quienes violan los derechos humanos, al mismo tiempo que de alguna manera se sanciona también a sus cómplices.

Solidarizarse hoy con la preocupación de que las instituciones funcionen en nuestros países, que los derechos económicos y sociales se impulsen y que se impida con sanciones adecuadas la violación a los derechos fundamentales, es estar al lado de las causas de los pobres. Y es estar al lado de la causa de la justicia y de esa fraternidad básica en la que todos decimos creer y que con tanta frecuencia olvidamos en el día de nuestras preocupaciones y ocupaciones.

(d) Y no podría terminar esta lista de caminos de solidaridad sin mencionar el compromiso personal con las luchas de los pobres. Comprometerse con su causa es un primer paso. Pero la causa de los pobres lleva siempre a ciertos tipos de lucha. Las luchas armadas, como decía, tienden a dejar mayor dolor que el que pretendieron evitar. Y como ya decía una de las más antiguas apologías del cristianismo, a la larga es más eficaz el preferir ser matado que matar. Pero esta posición no excluye de la participación en las luchas de los pobres.

En primer lugar porque la mayoría de sus luchas son profundamente pacíficas. Las luchas de los pobres comienzan siempre con métodos característicos de lo que a partir de este siglo se suele llamar como "no violencia activa". Son generalmente las respuestas de quienes defienden las situaciones injustas las que son directamente violentas. Como decía Mons. Romero, es esta violencia represiva la que generalmente lleva a la violencia subversiva. Ser solidarios con la no violencia activa de los pobres es la mejor manera de evitar ma- les mayores, porque los pobres recurren a la violencia, al menos en su dimensión masiva, sólo cuando una gran desesperación los invade. Unirse hoy a las luchas por la tierra, por los derechos humanos, incluidos los económicos y sociales, por la participación política, por la igualdad de la mujer, por el funcionamiento institucional, por la creación y difusión de las nacientes organizaciones de la sociedad civil, es asegurar el futuro de un mundo diferente y mejor que el que hoy existe.

En este contexto es importante recalcar que las luchas de los pobres entrañan, cada día con mayor fuerza, la que llamamos dimensión de género. La experiencia nos dice que allí donde se incorpora activamente a la mujer, en pie de igualdad con el hombre, a las luchas en defensa de la humanidad, los resultados son más rápidos y eficaces. En general, en nuestras sociedades latinoamericanas el machismo es una de las plagas más duras en la escala de la explotación humana. El mecanismo superior-inferior, que ya hemos mencionado, se centra muchas veces en el tema de la relación entre el hombre y la mujer, creando una cultura violenta en sí misma, antidemocrática y que niega la igual dignidad del género humano. Desde esa realidad difícilmente se llega a la verdadera liberación. Apoyar la lucha de la mujer hoy es garantizar un futuro más justo siempre, pues incluso desde su pobreza y situación de marginación social, la mujer ha mantenido en América Latina las dimensiones más profundas de la transmisión de valores.

Cada uno, en este contexto, deberá sopesar sus posibilidades, que van desde la participación directa en estas luchas en sus propios países, hasta la participación, incluso con medidas de no violencia activa, en todos los lugares donde se recibe el eco de la voz de la humanidad preguntándonos, una vez más, qué hemos hecho con nuestro hermano Abel. 